\title{
Analysis of Management Strategies of Corporate Public
}

\section{Relation Crisis}

\author{
Lixin Sun \\ Department of Information Management, Huai'an College of Information Technology \\ Jiangsu, Huai'an 223003, China \\ Tel: 86-517-8380-8260 E-mail: slx028@yahoo.com.cn
}

\begin{abstract}
Public relation crisis management has been an important research task in the modern management. Starting from the harms of the public relation crisis, the causes, management methods and principles of the public relation crisis are analyzed in this article. For public relation crisis management, enterprises should admit it timely so as to benefit from it.

Keywords: Public relation crisis, Public relation, Crisis Management

Under the complexity and uncertainty of the modern management environment, the pubic relation crisis may happen at any moment for each enterprise, such as the shrinking of "Sanzhu", the drinking of "Qianchi", the wing-broken of "Feilong", and the "Sanlu Powdered Milk Scandal", and similar tragedies occur again and again, and the effect of the public relation crisis management will directly influence the survival or extinction of the enterprise, and it is the key part of the development of modern enterprises. The public relation crisis management has been a new important research topic in the field of modern management.
\end{abstract}

\section{Harms of Public Relation Crisis}

The public relation crisis means the crisis related to the enterprise because of poor quality, labor dispute, legal wrangling and catastrophic failure exposed by the medias, and it will seriously affect the reputation of the enterprise. And it will often bring large loss, and damage the image of the enterprise, and even make the enterprise go bankrupt, such as the classical Jinan "Sanzhu”, Shandong "Qinchi”, Shenyang "Feilong”, "Toshiba" Laptop event, Nanjing "Guan Sheng Yuan", Belgian Coca Cola Poisoning event.

Public relation crisis has many characteristics such as abruptness, uncertainty, and variability. Because of the abruptness and uncertainty of the public relation crisis, it will largely harm the enterprise. In the society of information, many social conditions such as the modern information transfer and multi-channel spread make the influences of the information become more and more important, and if the enterprise lacks in the management experiences in the market economy conditions, the possibility that the public relation crisis happens in modern enterprises is much higher than it in the past. Because of the variability of the public relation crisis, it will occur by different faces in different periods. Although some public relation crises may be small, but improper management will extend it to be the disaster of the enterprise and some of them may weaken the enterprise at once and be the explosive disaster of the enterprise.

\section{Causes of Public Relation Crisis}

In the market economy system, each enterprise tries to pursue the maximization of benefits, and to drive the sustainable development of enterprise, no enterprise wants to get involved in the public relation crisis. However, the change of things is not often be changed by human will, and facing the complexity and uncertainty of the modern enterprise management environment, each enterprise should realize that the public relation crisis may happen at any moment. To get rid of the public relation crisis, and keep healthy development, enterprises should analyze and study the causes of the public relation crisis.

There are two main causes of the public relation crisis. One comes from the exterior of the enterprise, i.e. the social environment which supervises the enterprise too much, because the competitive opponents of the enterprise give attention to the weak part of the enterprise at any moment. The other one comes from the interior of the enterprise, i.e. the non-scientific management system and unhealthy management mechanism of the enterprise, because most enterprises lack in preventing measures for the public relation crisis management. Some enterprises can not realize the existence of the public relation crisis, and some enterprises can not realize the public relation crisis sufficiently, and more enterprises have not established effective early warning system. For these two aspects, the former composes the 
exterior factor of the public relation crisis, and the latter composes the interior factor of the public relation crisis.

Just as the fort always collapses from the interior, most enterprise public relation crises come from the interior factors of the enterprise, i.e. the daily work of the enterprise. These interior factors may be induced by long-term management faults, or one small mistake. And the exterior factor is often the fuse which leads to the public relation crisis of the enterprise.

Exterior causes take on their role through internal causes. In the mutual influences of interior causes and exterior causes, when the public relation crisis happens, enterprises should actively face and win the exterior causes, and the crisis may be beat. And if enterprises passively face the crisis, and the exterior causes are stronger than the interior causes, the enterprises may get in the large mess. When analyzing the causes of the public relation crisis, if enterprises could ascribe crisis to exterior causes, they will have large confident to win the crisis. On the contrary, if the crisis is more ascribed to interior causes, the confidence of the enterprise will be weakened. However, whether the public relation crisis comes from interior causes or exterior causes, enterprises should actively face it and try to avoid many passive ideas such as "a clean hand wants no washing" or "seeing but can not make up its mind".

\section{Public Relation Crisis Management}

The public relation crisis management has two functions, i.e. the prevention function and the management function. The prevention function includes all prevention works before the crisis. Though the avoidance of the crisis is the best approach of the crisis management, the prevention function is much more important. The management function includes all works after the crisis. Therefore, the two functions supplement each other and compose the complete system of the public relation crisis management. The public relation crisis management can be regarded as a "defensive war", and the prevention function is the first defense line, and active defensive strategies should be adopted. And the management function is the second defense line, and the firm defense strategies should be adopted, and the difference is that in the public relation crisis management, the implementation of the public relation crisis means the crisis has been broken out, and the organization or individual has been harmed to some extent.

The public relation crisis management is the main part of the crisis disposal. Once the public relation crisis happens, the crisis disposal of the enterprise is very important, because it directly influence the existence and survival of the enterprise itself. Therefore, in the daily marketing, enterprises should take the public relation crisis disposal as one important part of the management work. In the public relationship crisis disposal, enterprises should keep their eyes peeled, or else, they will lose clients' trusts, even the whole market. So following measures should be adopted when enterprises face the public relation crisis.

\subsection{Making the facts clear and studying the countermeasures}

When enterprises face the public relation crisis, they should not let well alone, and they should survey and control the development of the crisis at once. First, enterprises should organize relative personnel especially the general manager to participate in the survey of the crisis, and lead the public relation crisis disposal group, and make a comprehensive analysis to the crisis, such as what are the causes of the public relation crisis, whether they belong to the exterior causes or the interior causes, what are the state and the tendency of the crisis, which public will be impacted by the crisis, who are the direct victims of the crisis, and who are the indirect victims, and what the degree that the influence achieve, and what are the issuance channel and range of the information of the public relation crisis? And these problems should be made clear, because they are the direct references of the enterprise to adopt the remark measures.

\subsection{Requesting mediums to clarify the facts}

The facts of the public relation crisis should be declared to the media and the public as soon as possible. After the public relation crisis happens, except for the enterprise, the media, victims and competitive opponents all care about the crisis. For the media, a new drumbeating hotspot occurs, and it is easy to sympathize in the weak and more talks for victims, and is in the opposite state of the enterprise. For the victims, they try to request that the enterprise to offer a satisfactory answer for the crisis. And for the competitive opponents, they have a more competitive weight. Therefore, after the crisis happens, the enterprise should try to make clear the facts of the crisis as soon as possible, and spread the factors by virtue of the media. Only the facts can avoid various suspects and rumors. Truth is the best strategy of the enterprise facing the crisis. If the enterprise only covers up its errors, it will suffer the consequence of this own doing finally.

\subsection{Validated by the authorities and strengthening the reliability}

Enterprises should utilize the authority of relative institutions to solve the public relation crisis. In many instances, the authorized opinions will finally decide the disposal of the public relation crisis. Therefore, on one hand, enterprises should be humble and self-abuse and face the music and always put the public benefit on the first state, on the other hand, enterprises should persist in the principle. Only in this way, enterprises can not only control the crisis effectively, and enter a new progress. 


\section{Conclusions}

The public relation crisis management is a comprehensive and multi-polarized complex problem, and the enterprises should follow some basic public relation crisis management principles, i.e. the prevention is more important than the management, the active communication should adhere to the public relation, clients' benefit should be put on the first state in the concrete management, and the timeliness should persist. The achievement and implementation of the public relation crisis solution will not mean the end of the crisis. For enterprises, one important crisis management part is to summarize the lessons and experiences.

\subsection{Confirming in time is the start of the public crisis relation management}

For some enterprises, the key to success is to identify the weak part of the enterprise and judge whether it is small problem or potential "inflammable goods". Though some public relation crises are difficult to be predicted, but an accident, a mistake or some warning signals all will occur before most public relation crises happen, so enterprises could avoid these crises effectively if they realize these small mistakes. The problem is that most warning signals will be ignored completely. In the survival process of enterprises, warning signals will occur at any time, the ignored problem today may become the crisis tomorrow. Because our leaders are too busy in the daily management to spend time in stamping the "fire", we always care about some easy affairs, but ignore the warning signals. To confirm the crisis in time, enterprises should identify the warning signals before hand, including some potential problems and weaknesses. If some things are not normal in the enterprise, some enterprises should think about whether they should adopt actions to prevent the development of the crisis. The mangers who can identify the weaknesses and are wise will think of the old advertisement about the Fram Petrol Filter, "you can pay it now, or in future". You can deal with the small problem now to avoid large problem, or you can hope that small problem will be dispersed itself, but that might cost you much more. Of course, not all weaknesses or warning signals will turn into crises, but a good manager will believe that the warning signals may become crisis. Therefore, the warning signals must be emphasized, and relative opportunities should be offered to consider the short-term and long-term influences induced by these warning signals. In this stage, even the chemical students without experiences warn you "when you smell the odorless gas, it may be the carbon monoxide", you should care about the right aspect in this information. In total, you must understand others' opinions and validate it with yours. Undeniably, the costs may be large, and too much energies and materials need to be invested, but just as one old proverb tell us, "if you think it is not worth to do it, you can try nothing".

Enterprises should not evade the public relation crisis, and should not avoid the important points and dwell on the trivial for the consequence of the crisis, and should assume the responsibilities, and be practical and realistic to solve the crisis, and forthwith settle the crisis once find it. Once small problems occur, enterprises should check the whole management to grasp the causes of the crisis. If the crisis comes, the enterprise should inform the media immediately, and tell the society the real facts of the public relation crisis. The will and powers of all departments in the enterprise should be centralized to treat the crisis, and the survival is the most important thing at this moment.

\subsection{Right management is the unique approach to get rid of mess for enterprises}

The enterprise in the public relation crisis may "face hostility on all sides", such as news exposal, government criticism, client criticism even withdrawal, and public opinions, and the enterprise will bear large pressure. But this situation will not last all along, and there must be an "end", because the society is developing continually, and new things and crises will emerge in endlessly, and the public will not pay attention to certain one enterprise or crises, and people's attention will change with the time. But before the public's attention has not changed, the enterprise is still in the "critical period" like a heavy patient. Improper measure will arise the anger of the public, even ruin the future of the enterprise. In fact, facing the public relation crisis, any avoidance, disguise and cover are useless, and the wisest method is to face the facts practically and realistically, open necessary information channel to the public, and try to obtain the understanding and trust of the public as soon as possible.

\subsection{It is the important part of the public relation crisis management to benefit from the crisis}

Each public relation crisis contains not only the cause of failure, but the seed of success. Discovering, saving and cultivating will help to obtain this potential opportunity of success, which is the soul of the public relation crisis management. For enterprises, the development of the public relation crisis is not a good thing, but it can help the enterprise to drumbeat itself at the same time, only this drumbeating has large risk. If enterprises could treat the crisis calmly, and obtain the clients and the public's understanding by an active attitude, and adopt proper measures to save the adverse situation, and summarize lessons and experiences, and actively and intentionally improve the occasions to make the enterprise reborn in the crisis. In addition, the public relation crisis has happened, the enterprise can only face the facts, and use the facts to perfect the image of the enterprise, which is completely possible, because in the period of the public relation crisis, the enterprise is the focus of the news, and the hotspot of the public. Though the public care about the enterprise with hostility, it is also a kind of attention. Therefore, the enterprise should grasp the opportunity to turn the bad pubic relation crisis into an opportunity of drumbeating the enterprise. 
The public relation crisis management is a comprehensive and multi-polarized complex problem, and the enterprises should follow some basic public relation crisis management principles, i.e. the prevention is more important than the management, the active communication should be persisted in public relation, clients' benefit should be put on the first state in the concrete management, and timeliness should be adhere to.

\section{References}

Robert Heath (US), Interpreted by Wang, Cheng. (2001). Crisis Management. Beijing: China Citic Press.

Steven Cohen (US), Interpreted by Wang, Qiaoling. (2003). The New Responsible Administrator. Beijing: China Renmin University Press.

Sun, Lixin. (2003). “Another” Mess: Corporate Crisis of ZDG Company (Case). Master's Thesis of the MBA College of Dongbei University of Finance \& Economics. 